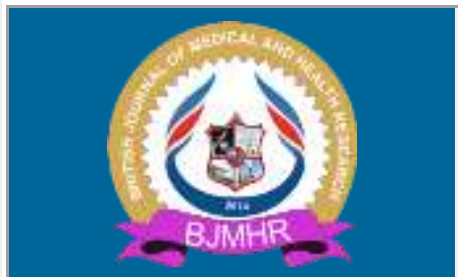

\title{
BJMHR
}

British Journal of Medical and Health Research

Journal home page: www.bjmhr.com

\section{Antimicrobial Activity of Hyptis suaveolens Flowering-tops}

\section{Pritam V. Chindarkar \\ Dravyagun Department, Matoshri Asarabai Darade Ayurved College, Babhulgaon, Tal. Yeola, Dist. Nashik, Maharashtra, India}

\begin{abstract}
The main objective of this present work is, to test the antimicrobial activities of crude ethanol extracts of leaves, stem and blooms from Hyptis suaveolens against bacteria- Escherichia coli, Staphylococcus aureus, Pseudomonas aeruginosa, Bacillus subtilis and Proteus vulgaris and, fungi- Aspergillus nigar and Candida albican. Antimicrobial properties of Hyptis suaveolens were evaluated using cup-plate diffusion and disc diffusion method. Analysis of the data revealed that, the ethanol extract of the blooms exhibited the highest antibacterial activity. It showed antibacterial activity against $S$. aureus: $34 \mathrm{~mm}$, B. subtilis; $36 \mathrm{~mm}$, E. coli; $35 \mathrm{~mm}, P$. valgaris; $21 \mathrm{~mm}$ and $P$. aerguinosa; $17 \mathrm{~mm}$. The ethanolic extract of the stem showed the highest antifungal activity on C. albican $(39 \mathrm{~mm})$. A. nigar was very sensitive to the ethanol extract of the leaves $(35 \mathrm{~mm})$. Results were compared to standard drugs; gentamicin and clotrimazole. Based on the current findings, it can be concluded that this Hyptis suaveolens flowering tops has antimicrobial activity, which is as significant as standard antimicrobial drugs against certain microorganisms.
\end{abstract}

Keywords: Hyptis suaveolens, Ethanol, Blooms, Antifungal, Antibacterial. 


\section{INTRODUCTION}

Hyptis suaveolens (Family: Lamiaceae) as an aromatic plant. It is common plant found in wasteland of North East India, Andaman and Nicobar Island, Deccan Peninsula. The plant internally used as a in infection of uterus, carminative, galactogogue, stimulant, antiseptic, sudorific, antispasmodic, antirheumatic, headaches and for treatment of cancer (Anonymous, 2001; Chopra RN et al., 1986; Rastogi R., 2001). The antimicrobial activity of seed oil from Hyptis suaveolens plant reported earlier (Bachheti RK., et al., 2015). The various Steam distillation, petroleum ether, and ethanol extracts from Hyptis suaveolens leaves were also evaluated for their antimicrobial activity in-vitro (Pati BR., et al., 2007). The essential oil from leaves of Hyptis suaveolens also evaluated for its antifungal activity (Moreira, ACP., et al., 2010).

As the plants leaves and seed already proven the antimicrobial activity so hypothesis was made that, flowering-tops (including the leaves, stem and blooms) of Hyptis suaveolens may have antimicrobial activity. After doing further litrature suvey it came to knew that there is no research work on 'flowering-tops' in relation to antimicrobial activity. Hence finally, the aim was draw in this study 'Antimicrobial Activity of Hyptis suaveolens Flowering-tops'

\section{MATERIALS AND METHOD}

\section{Procurement of Plant Material}

The flowering-tops (including the stems, leaves and blooms) of Hyptis suaveolens was collected from 'Yeola' region, Maharashtra, India, in the month of Sep-Nov 2019. Botanical identification was carried out from Dravyaguna Department of Matoshri Asarabai Darade Ayurved College, Dist. Nashik, Maharashtra, India and voucher specimen of the plant material has been deposited at college level.

\section{Preparation of Plant Material}

Fresh leaves, stem and blooms of Hyptis suaveolens are shade dried separately. Further powdered was prepared by passing through sieve \# 38, and separately kept in air tight polythene bags for further study.

\section{Chemicals and Instruments}

Solvents and reagents were procured from Research Lab-Fine Chem Industries, Mumbai, India. Some apparatus and other common glassware and instruments used for the study.

\section{Extraction}

The 50g powder of Hyptis suaveolens leaves, stem and blooms were extracted using ethanol separately. The Soxhlet's apparatus used for hot continuous extraction (6hrs) of plant material. After complete extraction the solvent was evaporated and concentrated to dry residue. \% yield was calculated for ethanol extract after drying under vacuum. All final extract obtained was 
used for further study.

\section{Preliminary Phytochemical Test}

The Preliminary Phytochemical study for various secondary metabolites (phytoconstituent's) carries out as per the procedure of C. K. Kokate (1994).

\section{Preparation of Extract for Evaluation}

The dilution used for all extracts was $100 \mathrm{mg} \mathrm{ml}^{-1}$. Ethanol was known to be inhibitory to the growth of bacteria. Therefore, the ethanol extracts was re-dissolved or suspended in methanol solvent.

\section{Microorganisms and medium}

The bacteria used were originally from the American type culture collection (ATCC), USA. They were obtained from the stock culture. Strains used were Escherichia coli ATCC25922, Staphylococcus aureus ATCC25923, Pseudomonas aeruginosa ATCC27853, Bacillus subtilis NCTC8236 and Proteus vulgaris ATCC6380. The fungi species used were Aspergillus nigar ATCC9763 and Candida albican ATCC7596. The media used for antibacterial tests were nutrient broth and Mueller Hinton agar. Whereby, nutrient broth and dextrose agar were used for antifungal tests. These media were prepared according to the standard methods.

\section{Antibacterial Activity}

\section{Cup-plate diffusion method}

Antibacterial activity of plant extracts was carried using cup-plate agar diffusion method (Murray et al. 2009) with some minor modifications. One $\mathrm{ml}$ from each standard bacterial stock suspension was mixed thoroughly with $20 \mathrm{ml}$ of sterile Molten Muellur Hinton agar (45 $\left.50^{\circ} \mathrm{C}\right)$, poured into sterile Petri-dishes and left to solidify. Then, four cup-shape wells $(10 \mathrm{~mm}$ diameter) were made in each plate using sterile cork-borer (No. 9). The agar disks were removed and four alternate cups were filled with extract using sterile adjustable pipettes. Four Petri-dishes with two alternate cups were used with the respective solvent instead of the extracts as control. The plates were then incubated in upright position for $24 \mathrm{hrs}$. After incubation period, the inhibition zones diameters were measured.

\section{Disc diffusion method}

The antibacterial assay for plant extract was also conducted using disc diffusion method as described by Abdel-Wahab et al. (2009). The nutrient agar solution (17 mL) was poured and kept overnight in a refrigerator. Whatman filter paper discs of $6 \mathrm{~mm}$ diameter were impregnated with $10 \mu \mathrm{L}$ of the solution of crude extract (at $4 \mathrm{mg} \mathrm{ml}^{-1}$ ) dissolved in dimethyl sulfoxide (DMSO). Standard disc of streptomycin sulphate $(10 \mu \mathrm{g} / \mathrm{disc})$ was used as positive control, while DMSO was used as a negative control. The Petri dishes were inverted and incubated for $24 \mathrm{~h}$ at $37^{\circ} \mathrm{C}$. Clear inhibition zones around the discs indicated the presence of antimicrobial activity. 


\section{Antifungal Activity}

The cup-plate agar diffusion method was adopted to assess the antifungal activity of prepared extracts (Murray et al., 2009). From each of the fungal stock suspension, $2 \mathrm{ml}$ was thoroughly mixed with $20 \mathrm{ml}$ of sterile molten Dextrose Agar $\left(45\right.$ to $\left.50^{\circ} \mathrm{C}\right)$, distributed into sterile Petridishes and left to solidify. Then, four cup-shaped wells $(10 \mathrm{~mm}$ diameter) were made in each plate using cork-borer (No.9). The agar disks were removed and alternate cups were filled with each extract using sterile adjustable pipettes. The plates were then incubated in the upright position for 24 to $48 \mathrm{~h}$ at a $37^{\circ} \mathrm{C}$. After incubation periods, the inhibition zones diameter were measured and the mean values were tabulated.

\section{RESULTS AND DISCUSSION}

\section{Physical Properties and Extraction Yield}

Results shown in Table 1 indicate the yield, color and texture of the different extracts.

Table 1: Physical Properties and Extraction Yield of Hyptis suaveolens Flowering top's

\begin{tabular}{llll}
\hline Plant part & Color & Texture & \% Yield \\
\hline Leaves & Dark green & Sticky & 11.52 \\
Stem & Green & Slightly sticky & 09.78 \\
Blooms & Brown & Gummy & 05.69 \\
\hline
\end{tabular}

\section{Preliminary Phytochemical Test}

Results shown in Table 2 indicates presence of phenolic compound, tannins, flavonoid, terpenes and steroids in flowering top's

Table 2: Preliminary Phytochemical Test of Hyptis suaveolens Flowering top's

\begin{tabular}{llll}
\hline Phytoconstituents & Leaves & Stem & Blooms \\
\hline Phenolic & ++ & +++ & +++ \\
Tannins & + & + & ++ \\
Flavonoid & ++ & + & +++ \\
Terpenes & +++ & - & ++ \\
Steroids & + & + & + \\
\hline
\end{tabular}

+++High Concentration; ++Moderate concentration; +-Low concentration;--Absent

\section{Antimicrobial Activity}

Ethanol extract of Hyptis suaveolens blooms showed antibacterial activity against S. aureus: $34 \mathrm{~mm}$, B. subtilis; $36 \mathrm{~mm}$, E. coli; $35 \mathrm{~mm}$, P. valgaris; $21 \mathrm{~mm}$ and P. aerguinosa; $17 \mathrm{~mm}$. The ethanolic extract of the stem showed the highest antifungal activity on C. albican $(39 \mathrm{~mm})$. A. nigar was very sensitive to the ethanol extract of the leaves $(35 \mathrm{~mm})$. Results were tabulated in Table 3 for antibacterial activity and antifungal activity. 
Table 3: Antimicrobial Activity of Hyptis suaveolens Flowering top's

\begin{tabular}{lllll}
\hline Microorganism & \multicolumn{5}{l}{ Zone of Inhibition $(\mathbf{m m})$} \\
& Leaves & Stem & Blooms & Gentamicin $\mathbf{( 4 0} \boldsymbol{\mu} / \mathbf{m l})$ \\
\hline Staphylococcus aureus & 31 & 30 & 34 & 23 \\
Bacillus subtilis & 30 & 28 & 36 & 25 \\
Escherichia coli & 29 & 31 & 35 & 32 \\
Proteus valgaris & 17 & 15 & 21 & 29 \\
Pseudomonas aerguinosa & 15 & 13 & 17 & 35 \\
Aspargellus nigar & 35 & 30 & 28 & -- \\
Candida albican & 35 & 39 & 29 & -- \\
\end{tabular}

\section{CONCLUSION}

This preliminary in-vitro study demonstrated that Hyptis suaveolens flowering top's effective against pathogenic microbes. It is an attempt made to prove flowering top's have antimicrobial activity. From the result we can revealed that the flowering top's may be collectively used for preparation of any pharmaceutical formulation.

\section{REFERENCES}

1. Anonymous, The wealth of India (Raw material), Vol. 5, Publication and Information Directorate, CSIR, New Delhi, 2001, 123-127.

2. Chopra RN, Nayar SL, Chopra IC, Glossary of Indian Medicinal Plants, CSIR, New Delhi, 1986, 46-46.

3. Rastogi R, Malhotra BN, Compendium of Indian Medicinal Plants, Vol. 5, Reprint ed., CDRI, Lucknow, 2001, 201-205.

4. Bachheti, RK., Rai, I., Joshi, A. Chemical composition and antimicrobial activity of Hyptis suaveolens Poit. seed oil from Uttarakhand State, India. Orient Pharm Exp Med. 2015; 15: 141-146.

5. Mandal, SM., Mondal, KC., Dey S., and Pati, BR. Antimicrobial activity of the leaf extracts of Hyptis suaveolens (L.) poit. Indian J Pharm Sci, 2007; 69 (4): 568-569.

6. Moreira, ACP., Edeltrudes de Oliveira Lima, Paulo Alves Wanderley, Egberto Santos Carmo, Evandro Leite de Souza. Chemical composition and antifungal activity of Hyptis Suaveolens (L.) Poit leaves essential oil against Aspergillus species. Braz J Microbiol. 2010; Jan-Mar; 41(1): 28-33.

7. Kokate CK. Handbook of Practical Pharmacognosy. Vallabh Prakashan, New Delhi, Edition 4, 1994:58-136.

8. Murray PR, Rosenthal KS, Pfaller MA. Medical Microbiology: Mosby Inc., 2009. 
9. Abdel-Wahab SI, Abdul AB, Zhew K, Fong SM. Antimicrobial and Free Radical Scavenging Activities of the Dichloromethane Extract of Goniothalamus umbrosus. Intl. J. Trop. Med., 2009; 4: 32-36.

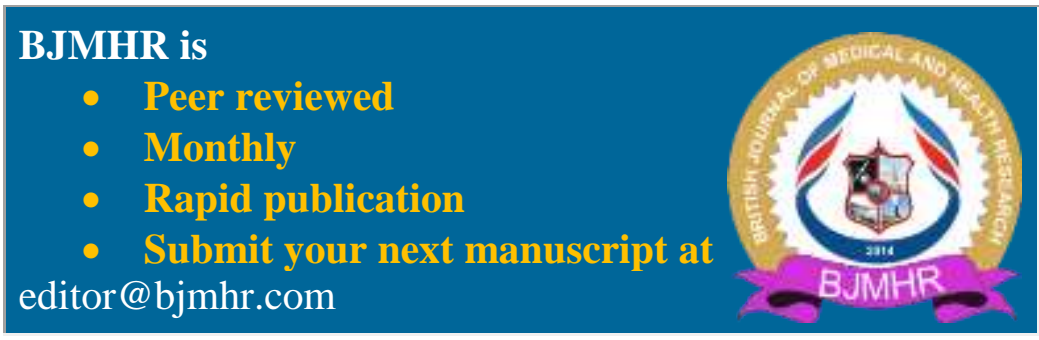

